Bioética

\section{Ato Médico}

O Conselho Federal de Medicina em sua resolução n 1.627/200 I passa a anuir o que é um ato médico.

Em seu art. $1^{\circ}$, define o ato profissional de médico como todo procedimento técnico-profissional praticado por médico legalmente habilitado, dirigido à prevenção primária, secundária ou terciária.

É através da leitura da exposição de motivos desta resolução que podemos observar a complexidade da tarefa de se conceituar o que venha a ser um ato médico, pois nesta podemos observar que: "o ato médico deve estar sempre limitado pela lei, pelo código de ética, pelas possibilidades técnico-científicas disponíveis, pela moralidade vigente na cultura e pela vontade do paciente"!.

A partir do que nos ensina Onere de Balzac de que "ao lado da necessidade de definir, corre-se o risco de confundir"2 ou como afirma Montaigne que "a maior parte da razão dos problemas do mundo são gramaticais" ${ }^{2}$, faremos alguns comentários.

\section{Comentário}

Do ponto de vista institucional, a resolução 1.627/2001 do CFM é vital, pois normatiza o que deva ser considerado um ato profissional de médico. Uma das funções do Conselho Profissional é a de definir o que é um ato profissional, assim como o é o da Constituição Federal instituir o estado democrático e assegurar o exercício dos direitos sociais e individuais.

Do ponto de vista jurídico entendo que esta resolução do CFM possa delimitar a responsabilidade profissiona $\beta$, auxiliando a justiça nos processos civis, pe- nais ou trabalhistas, assim como o dos conselhos de ética médica.

Já do ponto de vista da bioética, a questão é um pouco mais complexa, pois como todas as definições, ela é parcial, ela apenas nos sinaliza um norte que nos permitirá refletir sobre o que deva ser considerado como um ato médico. Esta resolução não nos diz quando o médico está em sua função ou quando socialmente ele deixa de estar na função de médico4. Por exemplo, em que momento o médico pode ter um relacionamento sexual com seu paciente? Nunca? Quando os dois assim o considerarem válido? Após algum tempo do fim do tratamento?

\section{Claúdio Cohen}

Referências

I. Conselho Federal de Medicina. Resolução n. I.627/200| .

2. Bobbio N. Autobiografia. Roma: Laterza; 1997.

3. Segre M, Cohen C. Bioética e medicina legal. In: Costa SIF, Oselka G, Garrafa V. Iniciação a bioética. Brasilia: Conselho Federal de Medicina; 1998.

4. Cohen C. Bioética e sexualidade humana nas relações profissionais. São Paulo: Associação Paulista de Medicina; 1999.

\section{Clínica Médica \\ TRATAMENTO DA ASMA}

Ao redor do mundo os esforços se concentram no sentido de estabelecer padronizações de diagnóstico, tratamento e ao mesmo tempo educar pacientes e equipes de saúde (devido à baixa adesão) no sentido de melhorar a atenção dada a esta doença, com vistas a reduzir morbidade e mortalidade.

No Brasil, os dados epidemiológicos são escassos. Numa população de médicos formados em 2000, apenas 30\% deles sabiam diagnosticar e/ou tratar asma. Deve-se desfazer o senso comum (pacientes eequipes de saúde) de que asma é uma condição clínica para ser tão somente atendida em pronto-atendimentos e pronto-socorros e conjuntamente reverter a baixa taxa de prescrição de corticoesteróides (apenas para 17\% em uma amostra de falecidos por asma), para tanto, desenvolvimento e divulgação de consensos são fundamentais entre os profissionais da saúde.

Várias são as causas de baixa adesão ao tratamento que pode chegar a $60 \%$ entre os adultos. Vários estudos mostram que a complexidade do tratamento e das medidas que envolvem o controle ambiental, a via de administração (melhor seria se fosse oral); os horários de uso, os diferentes dispositivos para inalação, os efeitos colaterais imaginados (fobia) os custos e o despreparo da equipe de atendimento colaboram para este alto padrão de não aderência, agravando-seo problema entre os adolescentes. Apenas a ação conjunta de equipes de saúde, famíliares e pacientes pode mudar este panorama.

\section{Comentário}

Os estudos sistemáticos não mostraram beneficios do emprego de antileucotrienos exantinas, deve-se atingir a dose máxima de corticóides inalatórios antes de se associar um destes medicamentos. A associação de $\beta 2$ agonistas de longa ação com um corticóide inalatório é superior ao uso destas medicações isoladas. As evidências favorecem a prescrição de demanda dos $\beta 2$ agonistas de curta ação, o seu uso regular resulta em eventos adversos. 
As evidências mostram que a administração de medicações por nebulização ou spray é igualmente eficaz e que o corticóide sistêmico, administrado no atendimento de urgência, abrevia o tempo de internação. $O$ uso de xantinas endovenosas não traz beneficios nesta situação, havendo mais efeitos adversos e riscos de intoxicação. A associação ou manutenção de corticóide inalatório agiliza o tratamento e a alta.

\section{Maria do Patrocínio Tenório Nunes}

Referências

I. Systematic Reviews of Asthma. In: The Cochrane Library, Issue I, 2002. Oxford Update Software.

2. Global Strategy for Asthma Management and prevention. NHLBIMHO. National Heart, Lung and Blood Institute; 1997.

3. Consenso Brasileiro de Asma. Projeto Diretrizes. Associação Médica Brasileira. Disponível em: URL:http:www.amb.org.br. Acesso em: março, 2002.

\section{Clínica Cirúrgica}

INFECÇÃO PERIANAL RECIDIVANTE PELO PAPILOMAVIRUS HUMANO

0 índice de recidivas dos condilomas perianais (4\% a $88 \%$ ) é atualmente um dos grandes desafios no manejo dos portadores de infecção pelo papilomavirus humano (HPV). Fatores como a imunidade sistêmica e local, e a agressividade viral estão implicados. Não há tratamento isolado nem esquema terapêutico universal- mente aceito que controle efetivamente a doença. É necessário erradicar as lesões subclínicas, que além de contagiosas podem evoluir e formar verrugas, controlar as lesões latentes que podem progredir para as formas subclínicas e clínicas, e avaliar e tratar os parceiros sexuais, que podem ser a fonte de re-contaminação.

Ainda não há esquema de tratamento disponível para o controle da forma latente. Duas vacinas anti-HPV vêm sendo testada em voluntários. Uma para evitar a infecção e outra para contê-la em sua fase latente. São esperanças para controlar a doença. Para as lesões subclínicas, diagnosticadas com uso de lentes de aumento (como, por exemplo, o colposcópio), o uso de substâncias tópicas e mesmo a evaporação com LASER é desejada. O seguimento deve ser feito e a periodicidade em que o exame será repetido dependerá do grau de proliferação celular, do tipo de neoplastia intraepitelial anal (NIA) e do poder oncogênico viral. Em doentes com proliferaçãa celular aumentada e NIA de alto grau de malignação ou tipo oncogênico de HPV, poderá ser repetido a cada três meses, durante o primeiro ano, semestralmente no segundo ano e anualmente do terceiro ano em diante. Nos casos de proliferação celular normal e NIA de baixo grau ou HPV não-oncogênico, semestralmente durante o primeiro ano e anualmente do segundo ano em diante. Se houver recidiva, retorna-se ao protocolo inicial. Caso haja reincidência no parceiro sexual, o exame deverá ser feito de imediato. Nas lesões clínicas, a aplicação tópica de podofilina a 25\% em vaselina sólida, nas lesões de pele, e de ácido tricloroacético, nas lesões da mucosa, ambas uma vez por semana, por quatro vezes, é efetiva. A conduta deve ser usada mesmo em portadores de condilomas grandes com indicação de tratamento operatório, pois, além de reduzir o número e tamanho dos condilomas, aumenta o período livre de recidiva, provavelmente por eliminar as lesões subclínicas.

Os parceiros sexuais devem ter os genitais, a região perianal, a cavidade oral e a orofaringe examinados. $\mathrm{Na}$ ausência de lesões visíveis, impõe-se exame para avaliar a presença de formas subclínicas. $\mathrm{O}$ exame histológico das lesões suspeitas e os métodos de identificação do DNA viral dos casos confirmados farão o diagnóstico. As lesões diagnosticadas serão tratadas e o seguimento realizado para controle de recidivas.

A procura por drogas que sejam mais efetivas para tratamento e controle da recidiva é antiga. Mais recentemente, substâncias imunomoduladoras têm sido testadas com sucesso: o imiquimod, o cidofovir e os interferons (IFN).

O imiquimod é modificador da resposta imunológica, agindo como modulador da imunidade celular, aumentando a produção local de IFN alfa, beta e gama e do fator de necrose tumoral alfa que provocam diminuição da carga viral. A aplicação diária da droga a $2 \%$ ou $5 \%$, sob a forma de creme ou gel, durante três a quatro semanas, é segura e efetiva erradicando os condilomas em $50 \%$ dos casos. Todavia, não deve ser usado em mucosas.

O cidofovir é agente antiviral nucleosídeo análogo. Impede a síntese de DNA viral pela inibição da DNApolimerase, diminuindo a duplicação viral, agindo principalmente nos DNAvírus que causam doenças cutâneas. O uso tópico, em forma de creme, ou intralesional são tidos como efetivos no tratamento e prognóstico das infecções provocadas pelo HPV, mesmo em doentes $\mathrm{HIV}+$. Não há efeito colateral sistêmico descrito. Todavia, recomenda-se redução 
da dose em portadores de insuficiência renal, uma vez que a droga tem excreção renal. Pode haver reação cutânea, por vezes acentuada, no local da aplicação.

\section{Comentário}

Os INFs têm demonstrado propriedades antivirais contra essas infecções. O IFN beta, intramuscular ou intralesional, três vezes por semana, num total de 12 a 15 injeções, mostrou eficácia, reduzindo em até $50 \%$ a área dos condilomas, com poucos efeitos colaterais que incluem cefaléía, astenia e mialgia. O IFN beta mostrou-se mais efetivo e menos tóxico que os IFN alfa e gama. O uso intralesional é muito doloroso e deve ser reservado para doentes com pequeno número de condilomas.

O objetivo dessas novas drogas não é apenas eliminar os condilomas, mas diminuí-los em número e volume, facilitando a ressecção cirúrgica, além de reduzir a taxa de decidiva. Já a maior eficácia do IFN é alcançada quando aplicado após a ressecção cirúrgica das lesóes.

\section{Sidney Roberto Nadal Carmen Ruth Manzione}

Referências

I. Gonzales-Sanchez LL, Martinez-Chequer JC, Hernandez-Celaya ME, Barahona-Bustillos E, Andrade-Manzano. Randomized placebo-controlled evaluation of intramuscular interferon beta treatment of recurrent human papillomavirus. Obstet Gynecol 2001; 97:621-4.

2. Nadal SR, Manzione CR, Galvão VM, Salim VR, Speranzini MB. Perianal diseases in HIV-positive patients compared with a seronegative population. Dis Colon Rectum 1999:42:649-54.

3. Nadal SR, Duarte Junior E, Manzione CR, Nadal PS, Speranzini MB. Tratamento tópico dos condilomas acuminados perianais em doentes HIV+. Rev Bras Coloproctol 1999; 19:79-82.

4. Syed TA, Hadi SM, Qureshi ZA, Ah SM, Kwah MS. Treatment of external genital warts in men with imiquimod $2 \%$ in cream. A palcebo-controlled double-blind study. J Infection 2000; 41:|48-5|.

5. Tyring SK, Arany I, Stanley MA, Tomai MA, Miller RL, Smith MH, et al. A randomized, controlled, molecular study of condylomata acuminata clearance during treatment with imiquimos. J Infect Dis 1998; 178:551-5.

\section{Ginecalagia}

\section{Consenso sobre COLPOCITOLOGIA ONCOLÓGICA}

Consenso realizado em Chicago, IIIinois, USA (200l)' abordou inúmeros aspectos sobre a colpocitologia oncológica, destacando-se entre os mais relevantes, o rastreamento, as obrigações do citopatologista em relação ao laudo e outros.

O consenso estabeleceu que o intervalo do rastreamento não deve ser anual e sim entre 2 a 5 anos; recomenda anualmente somente quando fatores de risco para câncer de colo uterino estiverem presentes ou se o último resultado da colpocitologia oncológica mostrar-se alterado, ou seja, lesões de alto ou baixo grau.

Orienta, ainda o consenso, a estimular o citopatologista para sugerir repetições de exames toda vez que anormalidades citológicas forem constatadas, além de sugerir que se utilize uma terminologia uniformizada para nominar os achados citológicos cervicais e para o diagnóstico das lesões. Considerou obrigatória a indicação da colposcopia e biópsia orientada em todos os casos de lesões intraepiteliais cervicais de alto grau ou câncer. $O$ consenso insiste também que nos casos de lesões de alto grau, as mulheres devam ser informadas de forma detalhada (verbal e por escrito).

\section{Comentário}

Inequivocamente, a colpocitologia oncológica representa o método de detecção e rastreamento mais apropriado para o câncer de colo uterino e de lesóes precursoras; de fato, esse método propedêutico proporcionou redução nas taxas de mortalidade por câncer de colo uterino nos EUA em 70\% (no perío do de 1950-1970) e de 40\% (no intervalo de 1970 a 1995), permanecendo estável nos últimos anos; estes resultados norte-americanos diferem expessivamente dos brasileiros, pois infelizmente o Brasil negligenciou a cobertura do rastreamento em todas as regiões do país.

Além da detecção precoce, a colpocitologia oncológica objetiva a monitorização das lesões precursoras no que tange a regressão ou progressão, colaborando na instituição da conduta apropriada, seja na repetição do exame ou na postulação do tratamento.

Os maiores obstáculos para a abordagem das lesões precursoras do câncer de colo uterino no Brasil são as diferentes freqüências com que elas se manifestam nas distintas regiões brasileiras, bem como as peculiaridades socioeconômicas de cada uma e da atuação dos sistemas públicos de saúde locais.

Todos esses fatores reforçam a necessidade de se criar consensos, como este de Chicago e depois atrelá-los a uma politica pública que pudesse ser difundida para toda rede de saúde brasileira. 
Nos países em desenvolvimento, como no Brasil, há uma enorme preocupação em relação aos exorbitantes custos dos tratamentos oncológicos; por isso, uma política nacional de saúde objetivando o rastreamento e detecção precoce de câncer do colo uterino, sem dúvida nenhuma, permitirá que esta afecção seja impedida de ceifar vidas de mulheres brasileiras em plena fase reprodutiva e produtiva. Assim, concordamos com o consenso de Chicago que postula a realização da colpocitologia oncológica a cada 2 a 5 anos em condições normais.

Consensos como o de Chicago devem ser estimulados, porque permitem o diagnóstico precoce, favorecendo o tratamento conservador e uma melhor qualidade de vida para as mulheres; permite, também, uma monitorização das lesões precursoras e impediria a realização indiscriminada e inoportuna de exames que causam expressivos custos para os serviços de saúde.

José Mendes Aldrighi Israel Nunes Alecrin

\section{Referências}

I. Vass L, Herbert A, Montanari G, Naryshkin S, Saraiya UB, Smith JH. Obrigations to provide appropriate patient management. Acta Cytol 200 I; 45:502-8.

2. Ries LA, Kosary CL, Hankey BF, et al., editors. SEER Cancer Statistic Review 1973-1995. Bethesda: National Cancer Institute, 1998.

3. Beneder JL, Anderson MB, Matisic JP. A comprehensive Program for cervical cancer detection and management. Am J Obstet Gynecol 1992; 166: 1254-59.

4. Celentano DD, Klassen AC, Weisman CS, Klassen AC, Weisman CS, Rosenshein NB. Druation of relative protection of screening for cervical cancer. Preventive Med 1989; 18:41|-22.

\section{Medicina Baseada em Euidências \\ Tratamento não OPERATÓRIO DAS LESÕES \\ TRAUMÁTICAS DE FÍGADO E BAÇO}

O tratamento não operatório (TNO) das lesões esplênicas em crianças é realizado rotineiramente na maioria dos centros de trauma, e o seu uso justificado em decorrência do risco de sepse pós-esplenectomia e das complicações associadas as laparotomias não-terapêuticas. Mais recentemente, estes conceitos têm sido extrapolados para o tratamento de crianças portadoras das lesões hepáticas. Nos últimos sete anos, diversos trabalhos foram publicados, avaliando a eficácia do TNO das lesões traumáticas do fígado e baço em adultos. Entretanto, ainda não é bem estabelecido se a experiência positiva obtida no TNO de crianças portadoras de lesões hepáticas e esplênicas possa ser de maneira direta extrapolada para o tratamento de adultos. Desta forma, a Eastern Association for the Surgery of Trauma (EAST) realizou uma revisão de 119 trabalhos reunindo evidências para a utilização do TNO em pacientes adultos.

As diretrizes propostas são baseadas neste estudo realizado pela EAST. Nível I de evidência: Não há dados suficientes (nível I de evidência) para estabelecer uma conduta padrão para o TNO das lesões traumáticas do fígado e baço. Nível II de evidência: As recomendações listadas a seguir são baseadas em estudos pros- pectivos não comparativos, ou retrospectivos confiáveis: (I) existem dados relevantes sugerindo que o TNO deva ser realizado em pacientes portadores de lesões traumáticas do baço e fígado em pacientes hemodinamicamente estáveis; (2) o grau da lesão hepática ou esplênica (avaliada através de tomografia), estado neurológico do paciente e/ou a presença de lesões associadas, não são contra-indicações para a realização do TNO; (3) a tomografia computadorizada de abdome é o método mais indicado para a identificação e avaliação da gravidade das lesões esplênicas e hepáticas. Nível III de evidência: As seguintes recomendações são baseadas em séries de casos retrospectivos ou em revisão de banco de dados: (I ) o estado clínico do paciente deve indicar a freqüência da realização de tomografias de controle; (2) a tomografia inicial deve ser realizada com o uso de contrastes via oral e via endovenosa, com a finalidade de facilitar o diagnóstico de lesões de vísceras ocas; (3) a permissão médica para o paciente reassumir as atividades habituais deve ser baseada na evidência da estabilização e cicatrização das lesões hepáticas e/ou esplênicas.

\section{Comentário}

As vantagens do TNO incluem a redução das taxas de laparotomias não-terapêuticas, com conseqüente diminuição da morbidade, dos custos e da utilização de sangue e hemoderivados. Em face da verdadeira epidemia de trauma, estudos prospectivos, multicêntricos, bem realizados e muito bem financiados, poderão fornecer grande quantidade de dados relevantes e contribuir para o tratamento otimizado das vítimas de traumas complexos.

Ruy Jorge Cruz JR Luiz Francisco Poli de Figueiredo 
Referência

Practice management guidelines for the non-operative management of blunt injury to the liver and spleen. Eastern Association for the Surgery of Trauma; 2000. Disponível em: URL: http://www.east.org.

\section{Obstetricia}

\section{MonitorizaÇÃo FETAL ELETRÔNICA NA INTERPRETAÇÃO DA FCF}

A monitorização da freqüência cardíaca fetal (FCF) pela cardiotocografia é método propedêutico que tem como objetivo principal a detecção precoce do sofrimento fetal. Este exame avalia as características da FCF pela análise visual dos traçados cardiotocográficos. Estando sujeita à subjetividade de cada observador, esta análise visual pode apresentar diversas interpretações. Com o intuito de padronizar os métodos utilizados na avaliação deste exame, foi publicado pelo "National Institute of Child Health and Human Development Research Planning Workshop"', em 1997, as recomendações para interpretação dos parâmetros da FCF. As definições estabelecidas neste artigo são destinadas para a interpretação visual de traçados obtidos no período intraparto, entretanto, são também aplicáveis ao período anteparto. Muitas características da FCF apresentam padrões dependentes da idade gestacional, devendo portanto ser sempre considerada na avaliação do traçado. Os componentes individuais dos padrões da FCF, que são definidos na análise, geralmente evoluem e se modificam com o tempo. Portanto, uma descrição completa do traçado engloba as seguintes características: linha de base, variabilidade da linha de base, presença de acelerações, presença de desacelerações episódicas ou periódicas, e, alterações dos padrões da FCF no tempo. Houve consenso entre os pesquisadores envolvidos que a análise dos traçados da FCF conferem elevados valores de predição para fetos com oxigenação normal. Vários padrões também foram identificados como sugestivos de asfixia fetal grave com elevado risco de lesões neurológicas ou óbito do feto. Estes padrões incluem desacelerações tardias ou variáveis recorrentes, ou bradicardia importante com ausência de variabilidade. Em muitos fetos, os traçados apresentam características intermediárias e a conduta clínica é controversa. Neste grupo, acredita-se que muitos progressos poderão advir da aplicação das recomendações oferecidas para a padronização da interpretação dos traçados, minimizando o risco de intervenções e reduzindo a ocorrência da acidemia metabólica fetal.

\section{Comentário}

Atualmente, a interpretação visual dos traçados cardiotocográficos, quando não padronizada nos pressupostos estabelecidos, está sujeita a grande variabilidade e pequena reprodutibilidade dos resultados. Os critérios estabelecidos pelo "National Institute of Child Health and Human Development Research Planning Workshop" procuram estabelecer parâmetros claros de avaliação dos traçados, aumentando a confiabilidade do método. A despeito dessa padronização, exames suspeitos e/ou alterados constituem ainda um desafio aos que trabalham com a avaliação do bem-estar fetal, principa/mente em gestações prematuras. A evolução do padrão cardiotocográfico do feto normalmente oxigenado para o observado na hipoxia grave, principalmente naquelas de intensidade suficiente para desencadear dano neurológico fetal, não é plenamente conhecida. A padronização de critérios para interpretação dos parâmetros da FCF proporciona meios de aprimorar a pesquisa nesta área, inclusive possibilitando a comparação entre estudos de diferentes instituições, para meIhor orientação na conduta clínica a ser adotada frente às alterações observadas nos traçados cardiotocográficos.

\section{Roseli Mieko Yamamoto Nomura}

Referência

National Institute of Child Health and Human Development Research Planning Workshop. Eletronicfetal heart rate monitoring: research guidelines for interpretation. Am J Obstet Gynecol 1997; 177:1385-90.

\section{Pediatria}

\section{HORMÔNIO DE CRESCIMENTO - PARTE II}

A Sociedade de Pesquisa de Hormônio de Crescimento reuniu-se para avaliar alguns aspectos do uso do hormônio (GH) e verificar se algumas preocupações com sua utilização encontram respaldo na literatura especializada.

Ao lado da análise sobre a segurança de seu uso em crianças, a Sociedade debruçou-se sobre os aspectos de segurança com o uso do $\mathrm{GH}$ em adultos. Metabolismo da glicose - A prevalência de diabetes mellitus (DM) está aumentada em adultos hipopituitários e as ações metabólicas do GH incluem antagonismo à insulina. Recomenda-se que o metabolismo glicêmico seja avaliado em todos os 
pacientes, antes e após substituição com GH. DM ou tolerância a glicose alterada não são contra-indicações do uso de GH. O exame de fundo de olho deve ser periodicamente realizado e, e bem que uma retinopatia não proliferativa não seja motivo de descontinuação do uso de $\mathrm{GH}$, o desenvolvimento de retinopatia proliferativa exige a suspensão de uso do GH. Retenção de fluidos - Pode ocorrer especialmente nas fases iniciais do uso do $\mathrm{GH}$. Parcialmente, isto reflete a normalização da hidrataçãa tecidual induzida por $\mathrm{GH}$ e dependente de dose. Peso, história clínica e examefíisico são capazes de identificar tal ocorrência. Redução de dose no caso de sintomas persistentes deve ser considerada. Cuidado especial em pacientes com insuficiência cardíaca congestiva. Interação com outros hormônios - $\mathrm{O}$ GH aumenta a conversão de T4 a T3 e pode desmascarar um hipotireoidismo incipiente. $\mathrm{O} \mathrm{GH}$ pode diminuir a concentração de cortisol total diminuindo a globulina ligadora (CBG). Pode também reduzir a biodisponibilidade de cortisol, aumentando sua conversão a cortisona. A possibilidade de uma insuficiência adrenal deve ser considerada durante aterapia. Função cardíaca e lipoproteínas - A prevalência aumentada de doença cardiovascular observada na acromegalia ativa não pode ser extrapolada para o adulto hipopituitário em reposição de $\mathrm{GH}$. Desta forma, a monitorização da função cardiovascular deve seguir os padrões para população normal. A substituiç̧ão de $\mathrm{GH}$ no adulto aumenta os níveis séricos de lipoproteínas. São incertas as implicações (se é que há) dessa elevação e isto deve ser pesado contra os benefícios da instituiçãa do tratamento com GH. Risco de câncer e recorrência de tumor Tem sido documentada uma incidência aumentada de certas doenças malignas (especialmente recorrência de tumor) em adultos hipopituitários, mas não há evidência de quetal fato associe-se à reposição com GH. Aspectos de segurança em tratamento farmacológico de $\mathrm{GH}$ em adultos - Uso em Terapia Intensiva - Estudos demonstram que a mortalidade dobra em pacientes gravemente enfermos tratados com altas doses de $\mathrm{GH}$. Tratamentos farmacológicos com GH - Qualquer tratamento com $\mathrm{GH}$ que não seja de substituição em pacientes deficientes deve ser considerado farmacológico. Em condições espećficas em que se esteja considerando o tratamento farmacológico, devem ser coletados dados de segurança e protocolos devem ser desenvolvidos, como se estivéssemos testando uma nova droga.

\section{Comentário}

Cada vez mais tem havido indicações para o uso de GH em pacientes adultos, que foram crianças que cresceram normalmente e, por conseqüência, produziram seu GH nessa fase de crescimento. Os cuidados a serem tomados em tais pacientes são bem abordados pela Sociedade de Pesquisa em GH, e alertas quanto a doses farmacológicas devem ser tomados em sua devida conta. A/guns "mitos" têm sido derrubados, como a contra-indicação do GH em casos de neoplasias e, extremamente importante, o seguimento dos pacientes, com avaliações periódicas com intuito de se detectar alteraçóes que podem levar à suspensão da medicação (como retinopatia proliferativa, por exemplo) nunca deve ser esquecido.

\section{Durval Damiani}

Referência

Growth Hormone Research Society. Critical evaluation of the safety of recombinant human growth hormone administration: statement from the Growth Hormone Research Society. J Clin Endocrinol Metab 200 I; 86: 1868-70. 